\title{
Political economy of renewable resource federalism
}

\author{
James N. Sanchirico, ${ }^{1,9}$ Julie C. Blackwood, ${ }^{2}$ Ben Fitzpatrick, ${ }^{3}$ David M. Kling, ${ }^{4}$ Suzanne Lenhart, ${ }^{5}$ \\ Michael G. Neubert, ${ }^{6}$ Katriona Shea, ${ }^{7}$ Charles B. Sims, ${ }^{8}$ and Michael R. Springborn ${ }^{1}$ \\ ${ }^{1}$ Department of Environmental Science and Policy, University of California, Davis, Davis, California 95616 USA \\ ${ }^{2}$ Department of Mathematics and Statistics, Williams College, Williamstown, Massachusetts 01267 USA \\ ${ }^{3}$ College of Science and Engineering, Loyola Marymount University, Los Angeles, California 90045 USA \\ ${ }^{4}$ Department of Applied Economics, Oregon State University, Corvallis, Oregon 97331 USA \\ ${ }^{5}$ Department of Mathematics, University of Tennessee, Knoxville, Tennessee 37996 USA \\ ${ }^{6}$ Department of Biology, Woods Hole Oceanographic Institution, Woods Hole, Massachusetts 02543 USA \\ ${ }^{7}$ Department of Biology, Pennsylvania State University, University Park, Pennsylvania 16802 USA \\ ${ }^{8}$ Department of Economics, University of Tennessee, Knoxville, Tennessee 37996 USA
}

Citation: Sanchirico, J. N., J. C. Blackwood, B. Fitzpatrick, D. M. Kling, S. Lenhart, M. G. Neubert, K. Shea, C. B. Sims, and M. R. Springborn. 2021. Political economy of renewable resource federalism. Ecological Applications 00(00):e02276. 10.1002/eap.2276

Abstract. The authority to manage natural capital often follows political boundaries rather than ecological. This mismatch can lead to unsustainable outcomes, as spillovers from one management area to the next may create adverse incentives for local decision making, even within a single country. At the same time, one-size-fits-all approaches of federal (centralized) authority can fail to respond to state (decentralized) heterogeneity and can result in inefficient economic or detrimental ecological outcomes. Here we utilize a spatially explicit coupled natural-human system model of a fishery to illuminate trade-offs posed by the choice between federal vs. state control of renewable resources. We solve for the dynamics of fishing effort and fish stocks that result from different approaches to federal management that vary in terms of flexibility. Adapting numerical methods from engineering, we also solve for the open-loop Nash equilibrium characterizing state management outcomes, where each state anticipates and responds to the choices of the others. We consider traditional federalism questions (state vs. federal management) as well as more contemporary questions about the economic and ecological impacts of shifting regulatory authority from one level to another. The key mechanisms behind the trade-offs include whether differences in local conditions are driven by biological or economic mechanisms; degree of flexibility embedded in the federal management; the spatial and temporal distribution of economic returns across states; and the status-quo management type. While simple rules-of-thumb are elusive, our analysis reveals the complex political economy dimensions of renewable resource federalism.

Key words: bioeconomics; metapopulation; Nash equilibrium; spillover; sustainability.

\section{INTRODUCTION}

The authority to manage natural capital tends to fall within political boundaries instead of aligning with ecological systems. Renewable biological resources comprise one category of natural capital that is particularly prone to mismatches between the spatial extent of the resource and political boundaries. Addressing problematic mismatches between the spatial extent of renewable resources and boundaries of management authority is critical for sustainability (Crowder et al. 2006).

In cases where natural resources cross international boundaries, a large multidisciplinary literature has studied the problem of structuring international agreements

Manuscript received 18 June 2020; revised 18 August 2020; accepted 9 September 2020. Corresponding Editor: Éva E. Plaganyi.

${ }^{9}$ E-mail: jsanchirico@ucdavis.edu to balance member country incentives while ensuring sustainable outcomes for the resources governed under the agreement (Munro 1979, Levhari and Mirman 1980, Fischer and Mirman 1992, 1996). Voluntary agreements among countries have had mixed success with addressing management failures for resources that cross international boundaries (Barrett 2016, Dannenberg and Barrett 2018).

Within countries, boundaries of management authority are in principle more malleable and typically determined by the system of government. In the United States and other countries with federal systems of government, semi-autonomous regions (i.e., states, provinces, territories) exist under a central federal government. In these systems, the authority to manage a renewable resource may be held by the federal government, or it may be decentralized and held by one or more states, provinces, or territories. For example, in the United States, coastal states or state coalitions (e.g., 
Atlantic States Commission) manage a fishery within three nautical miles ( 1 nautical mile $=1.852 \mathrm{~km}$ ) of shore, often in partnership with the National Oceanic and Atmospheric Administration. In Canada, provincial governments have primary authority to control the capturing and killing of wildlife within their jurisdiction, while the federal government has superseding authority to protect wildlife designated as species at risk (Illical and Harrison 2007).

Our research addresses a fundamental question: for a given renewable resource, what trade-offs arise when management authority may be held at either the federal government level (centralized) or be decentralized to state, provincial, or territorial governments?

Renewable resource federalism is not just of theoretical interest, as many countries are reevaluating the level of management authority over resources. For example, several countries in Southeast Asia have undergone a transformation in the last $10 \mathrm{yr}$ to more decentralized control of natural resources (Aden 2001). In the European Union (EU), a multinational entity with federal characteristics, controversy over the EU's Common Fisheries Policy was a prominent issue in the United Kingdom's referendum over leaving the EU and the subsequent negotiations to leave the bloc (Phillipson and Symes 2018). In the United States, the Modern Fish Act (S.1520) is moving the management of the recreational red snapper fishery from federal to state authorities. Lands owned or administered by the federal government comprise about $21 \%$ of the area of the lower 48 states (Libecap 2018). One motivation for the "land transfer movement" that advocates handing ownership or authority of federal lands to the states is greater control by states over the renewable resources they contain (Ruple 2018).

Pollution management in federal systems also poses trade-offs on management authority (Oates 2001). In the United States, regulatory authority has oscillated between periods of relatively greater state or federal management of pollution (Elliott et al. 1985). Literature on environmental federalism has shown that decentralized management can be more economically efficient due to the availability of better information about local costs and benefits of pollution control, beneficial effects of inter-state regulatory competition, or the relative inflexibility of centralized management (Oates and Schwab 1988, Wellisch 1995, Ulph 2000, List and Mason 2001, Kunce and Shogren 2002, 2005, Muller and Mendelsohn 2009). Two drawbacks of decentralization are also noted: (1) trans-boundary spillovers from pollution control policies and (2) the incentive for individual states to "race to the bottom" by lowering standards to attract polluting economic activity. Oates (2001:9) succinctly summarizes the trade-offs highlighted in the pollution control case: "[W]e are left with a choice between two alternatives: suboptimal local decisions on environmental quality or inefficient uniform national standards. And which of these two alternatives leads to a higher level of social welfare is, in principle, unclear."
Renewable resource federalism shares a number of parallels with pollution control. For example, an emerging theoretical literature illustrates how centralized management of renewable resources has the advantage of a broader potential spatial scale of intervention (Smith et al. 2009, Sims et al. 2010, Epanchin-Niell and Wilen 2014, Kling et al. 2016), while decentralized management can perform well through greater flexibility with respect to local conditions of a resource (Sanchirico and Wilen 2005) or local stakeholder preferences (Costello and Kaffine 2017). Regulatory authority will oscillate between periods of relatively greater state or federal management of renewable resources as control of the executive and legislative branches shift.

Here we illustrate how renewable resource federalism trade-offs are more nuanced than the prior literature has demonstrated. Specifically, we show how the magnitude and nature of the trade-offs depend on the factors driving local differences (ecological or economic), the kind of policy instruments employed (standard vs. market based), the status quo management regime (central or decentralized), and how the benefits and costs of a management regime are distributed across jurisdiction. Considering these dimensions together is crucial in order to illuminate the political-economy issues surrounding different scales of management and to provide a richer picture of the benefits and costs to policymakers. For example, questions about the preferred scale and scope of resource management often hide disagreements among local governments. These disagreements, however, are critical since shifts to more efficient management of the resource may require consensus among all impacted jurisdictions.

\section{Models And Results}

This paper evaluates the performance of federal (centralized) and state (decentralized or sub-national) management of renewable resources in terms of the economic value of extraction from a resource stock over time. We base our analysis on a simple but flexible spatial-dynamic bioeconomic optimal control model of a fishery (see Methods for more details). The model assumes a single country's resource stock spans two states. Here we use "state" to refer to a sub-national management jurisdiction. The model includes dynamic variables that represent the resource stock biomass that resides under the authority of each state. State-level fish stocks are connected spatially through biological dispersal that depends on the relative biomass density in the two states (Sanchirico and Wilen 1999). We consider two sources of state-level heterogeneity that shape the degree of biomass spillover in the system: biological (differences in resource productivity in each state) and economic (difference in harvesting costs in each state). Following the pollution control literature, we investigate how heterogeneity in local conditions interacts with spillover across states (here rate of fish dispersal) to determine the 
trade-offs associated with management at different levels of government.

The human component of our coupled human-natural system model accommodates governance alternatives consistent with federalism and fishing. We consider several different federal management types, including: the optimal economic management approach that maximizes system-wide economic returns using a dynamic and spatially explicit policy (commonly labeled the "first-best" policy); and a selection of policies that apply uniformly over space. Federal management that is dynamic, forward looking, but spatially uniform represents a one-size-fits-all approach that is typical of federal systems (Arrow et al. 1996). In practice, spatially uniform policies may be chosen due to a lack of information needed to tailor policies to local conditions; however, they are perhaps more likely to be motivated by equity or procedural fairness considerations. An important point is that uniform policies will in general fail to match the system-wide performance of the first-best due to the heterogeneity in the states. We further divide spatially uniform federal policies into two categories: a uniform limit on fishing effort (command-and-control) and a uniform quota price (market-based). Uniform effort may be interpreted as a form of social policy aimed at preserving employment in the resource sector in each state. The uniform quota price is the efficient market solution when tradeable quota markets are linked and trading of quota between the regions occurs on a one to one basis. See Methods and Appendix S1: Sec S1.3 for additional details.

The alternative to federal management is decentralization, where each jurisdiction or state manages its resource independently. In this setting, states are forward looking and behave strategically in their own interests knowing the actions of the other states. We operationalize this alternative as the outcome of a non-cooperative dynamic game. Both states attempt to maximize their economic return from harvesting the resource over time by choosing effort levels in each period subject to the actions of the other state. The outcome is that states pursue a dynamic harvesting policy that is a Nash equilibrium of the interstate game (Kamien and Schwartz 1991). Our analysis therefore differs from most of the prior pollution or renewable resource federalism literature that only look at the long-run equilibrium outcomes or consider special functional forms that simplify the dynamic solutions to be time invariant (Costello and Kaffine 2017). Solving for dynamic paths of harvesting effort in the interstate game is a challenging numerical problem. Adapting methods from the engineering and optimal control literature (Guangyan et al. 2016, Nikooeinejad et al. 2016), we develop a numerical approach to quickly and robustly solve for the Nash equilibrium dynamic paths.

Under either governance alternative, federal or state, the objective is to maximize the discounted profit generated by harvesting the resource over time (net present value, NPV). We assume a simple market structure where the per-unit price of the resource is the same in both states and is not responsive to overall output. An implication of this assumption is that choices made by another state are only relevant to a particular state by virtue of the effect on resource (fish) dispersal, which may in turn influence state-level resource productivity and levels. These two regulatory alternatives capture a key trade-off in federal systems: state management can tailor policies to local conditions but federal management has more control over spillovers among states.

To facilitate comparison across management regimes, we consider a common initial condition for the fishery where an absence of regulation results in the fish stock in each state being depleted to $20 \%$ of the state-level carrying capacity. Starting from this point, fishing effort may either be regulated by the federal government or by the states and in either case the fish population will undergo a period of rebuilding. Before pitting the different centralized and decentralized regimes against each other, we compare each against the first-best spatially explicit time-varying policy. Because by definition the first-best achieves the optimal paths of effort and stock and greatest NPV, we measure performance of each regime as the percent decrease in the aggregate NPV of profits (Eq. 3) under a given management type, relative to the NPV under first-best management (Fig. 1).

We evaluate performance in the presence of each source of spatial heterogeneity (biological and economic) by varying the degree of heterogeneity across a continuum of rates of fish dispersal from none to almost half of the growth rate. With no heterogeneity, each state is identical and both one-size-fits-all federal policies achieve the first-best outcome of maximized fishing profits (Fig. 1A, B, D, E). Decentralized state-level management achieves the first-best outcome with no biological dispersal (Fig. 1C and F), as what is best for each state in this case is best for the system (regardless of how different the conditions in the states are).

Neither spatially uniform federal management nor state management is able to achieve the first-best outcome with dispersal between heterogeneous states. Intuitively, the greater the heterogeneity in local conditions, the better policies that reflect the underlying heterogeneity will do (state) and the greater the spillover or dispersal between the states, the better policies at larger scales will do (federal). Indeed, we find these patterns across both economic and ecological heterogeneity. For instance, since states optimize their management with respect to local resource conditions (along with the behavior of the other state), we find that the losses from decentralized state-level management decrease with increased biological heterogeneity across states and increase with greater rates of dispersal (Fig. 1C and F). In contrast, the performance of federal management declines with increased heterogeneity since policies cannot be tailored to local resource conditions. 


\section{Biological heterogeneity}

A

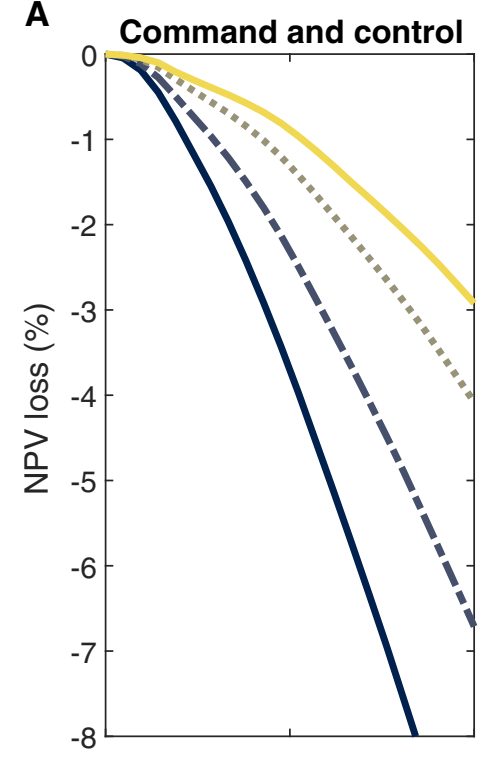

B

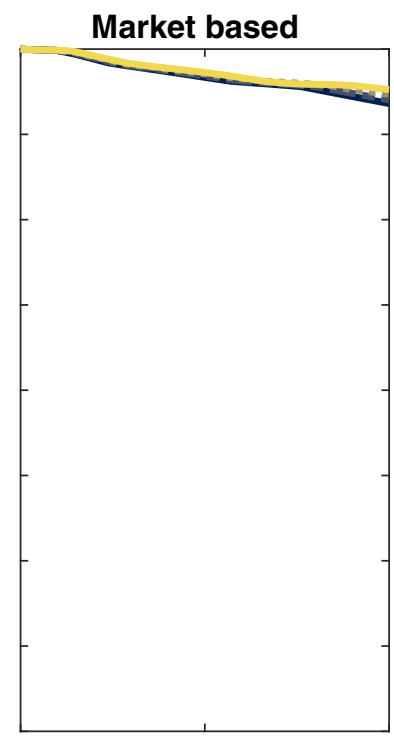

C

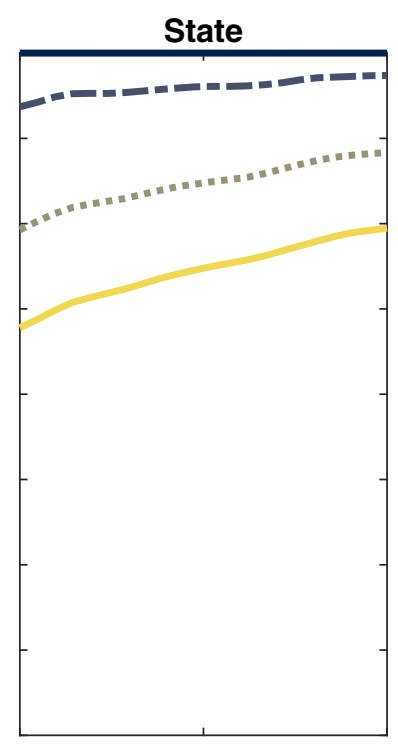

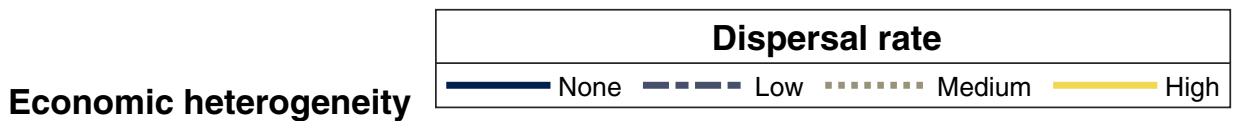

D

E

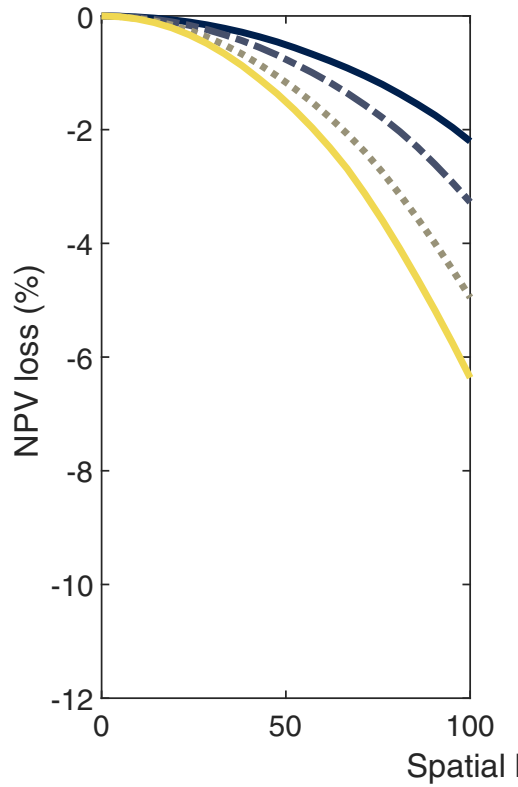

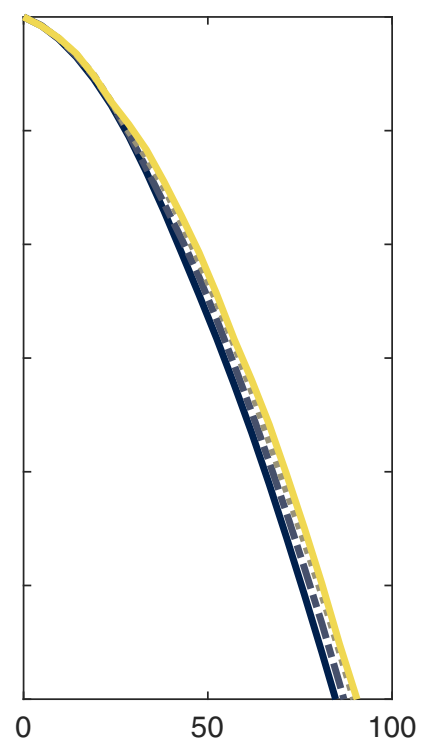

$\mathbf{F}$

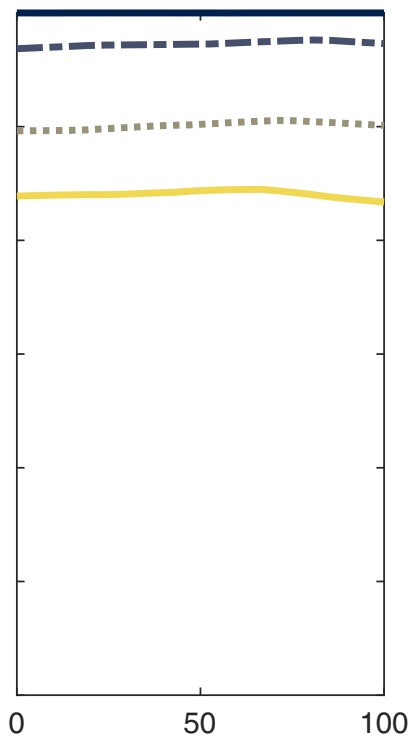

FIG. 1. Percent loss in the net present value (NPV) of fishery profits under uniform federal and state management (vertical axis) relative to the first-best outcome. We measure percent loss varying the degree of interstate (economic or biological) heterogeneity along the horizontal axis. Within each panel, the four lines correspond to zero $(d=0)$, low $(d=0.10)$, medium $(d=0.26)$, and high $(d=0.40)$ dispersal rates. We consider $(\mathrm{A}-\mathrm{C})$ biological heterogeneity and $(\mathrm{D}-\mathrm{F})$ economic heterogeneity, where the level of both types of spatial heterogeneity given by the horizontal axis. Biological heterogeneity is given by the percent difference in intrinsic growth rate $\left(r_{1}\right)$ in state 1 relative to state 2 . Economic heterogeneity is given by the percent difference in cost of harvesting $\left(c_{21}\right)$ in state 2 relative to state 1 . The three columns show, respectively, performance under a policy of (1) command and control (uniform effort), (2) market-based regulation (uniform marginal profit), and (3) state-level management. 
Underlying the NPV results are transitional paths of fishing effort and fish stocks in the different management regimes (all of which start at the same initial conditions, which are below the long-run equilibrium levels; Fig. 2). Specifically, in each management regime and heterogeneity scenario, we find that fish stocks increase over time toward management regime specific equilibrium levels (steady states). Relative to the first best, state management results in increased exploitation of the resource in both states (lower fish stocks). The two federal uniform policies straddle the first best solution where in one state fish stocks are higher, and in the other the fish stocks are lower. The optimal one-size-fits-all policies represent the "averaging" effects of these sort of policies relative to the first-best policy (Sanchirico and Wilen 2005). While intuition would lead one to conclude that decentralized control has the highest rates of exploitation and lowest stock levels, we find that in some cases the one-size-fits-all approach can in fact lead to lower stock levels due to the averaging effect (see, e.g., Fig. 2E). Because the goal also is to rebuild the populations, harvest moratoriums are part of the solution but the duration depends on the management regime. For example, in the case of biological heterogeneity, the moratorium in state 1 is longer under the uniform-effort regime than in the first-best and the market-based strategy is much shorter. The implication is that the observed dynamics of fish populations in coupled natural-human systems are as much related to their management regimes as they are to the biology.

While greater heterogeneity increases the losses associated with federal management, the magnitude of these losses depends on the source of heterogeneity and the dispersal rate. Market-based policies are better equipped to handle small differences in economic value across the system, as we find in the case of biological heterogeneity (Fig. 1A and B). The larger differences in economic values that occur when we differentiate the conditions based on the cost of harvesting, however, are more costly to average over and thus result in greater losses (Fig. 1D and E). Dispersal in this case acts to mitigate some of the losses in the market-based federal policy, as the magnitude and direction of net dispersal is endogenous and biomass is moving along the economic gradient from high cost fishing areas to lower cost fishing areas (Appendix S1: Fig. S1C and D).

Under uniform effort federal policy, the role of biological dispersal on the magnitude of the losses is more nuanced due to the manner in which the policy interacts with the biological dispersal mechanisms (Appendix S1: Fig. S1 A and B). In the case of biological heterogeneity, dispersal flows from the high productive (greater economic value) to the low productive state (lower economic value) in essence making the lower productive state more productive with higher economic value. Spillover, therefore, mitigates the cost of the uniform effort constraint, as it reduces the differences in productivity and economic value. On the other hand, with economic heterogeneity, net spillover is essentially zero in the command and control for all periods (Appendix S1:Fig. S1C and D). At the same time in the first best policy, the manager is able to align the biological and economic gradient (spillover is moving to the low cost area due to fishing effort levels) to maximize the value of the fishery. The losses grow with greater heterogeneity as the value of aligning the two gradients in terms of the overall value of the system increases.

Certain insights from comparing federal and state management types to the first-best policy carry over to comparing renewable resource federalism alternatives to each other. We find that a more spatially connected resource (higher dispersal rates) favors federal one-sizefits-all policy while greater heterogeneity favors management by the states (Fig. 3). These gains increase toward the extremes: no heterogeneity and high dispersal ( $y$-axis in Fig. 3) and high heterogeneity and no dispersal ( $x$ axis in Fig. 3). Away from the extremes, the relative returns across the federal or state management regimes vary and the location where preference for one over the other changes based on the policy and source of heterogeneity (black line in Fig. 3A, B, D, and E).

With biological heterogeneity, the market-based federal regulation is always preferred to the uniform effort policy (Fig. 3C). Based on aggregate value derived from the system, federalism questions about the optimal level of regulation should narrow to the choice between statelevel management and federal market-based policies. However, with economic heterogeneity, discussions around federalism are more complex, as the preferred management regime varies depending on the dispersal and heterogeneity levels. Market-based policies are only preferred to command and control with low heterogeneity (Fig. 3F). This finding is consistent with larger losses from market-based policies under economic heterogeneity (Fig. 1D and E). That command-and-control policies may outperform market-based policies is also consistent with results from the pollution control literature when pollutants disperse over space (e.g., Oates et al. 1989). Therefore, when states vary in the cost of harvesting, framing the federalism question as a choice between federal versus state management can be misleading without also acknowledging the different policies that can be implemented at the federal level.

While focusing on the total value of the system provides insights into the political-economy of federalism debates, renewable resource federalism also raises important questions of fairness. The distribution of economic returns and ecological outcomes across states can vary by management type causing states to disagree about the preferred level of management. Disagreement is not inevitable however. Measuring a state's preferred level of management based on their NPV, we find that there are some cases where both states favor the same management regime. For example, both states prefer federal management (dark blue regions in Fig. 4) when the states are similar and the resource is mobile. Likewise, 


\section{Biological heterogeneity}
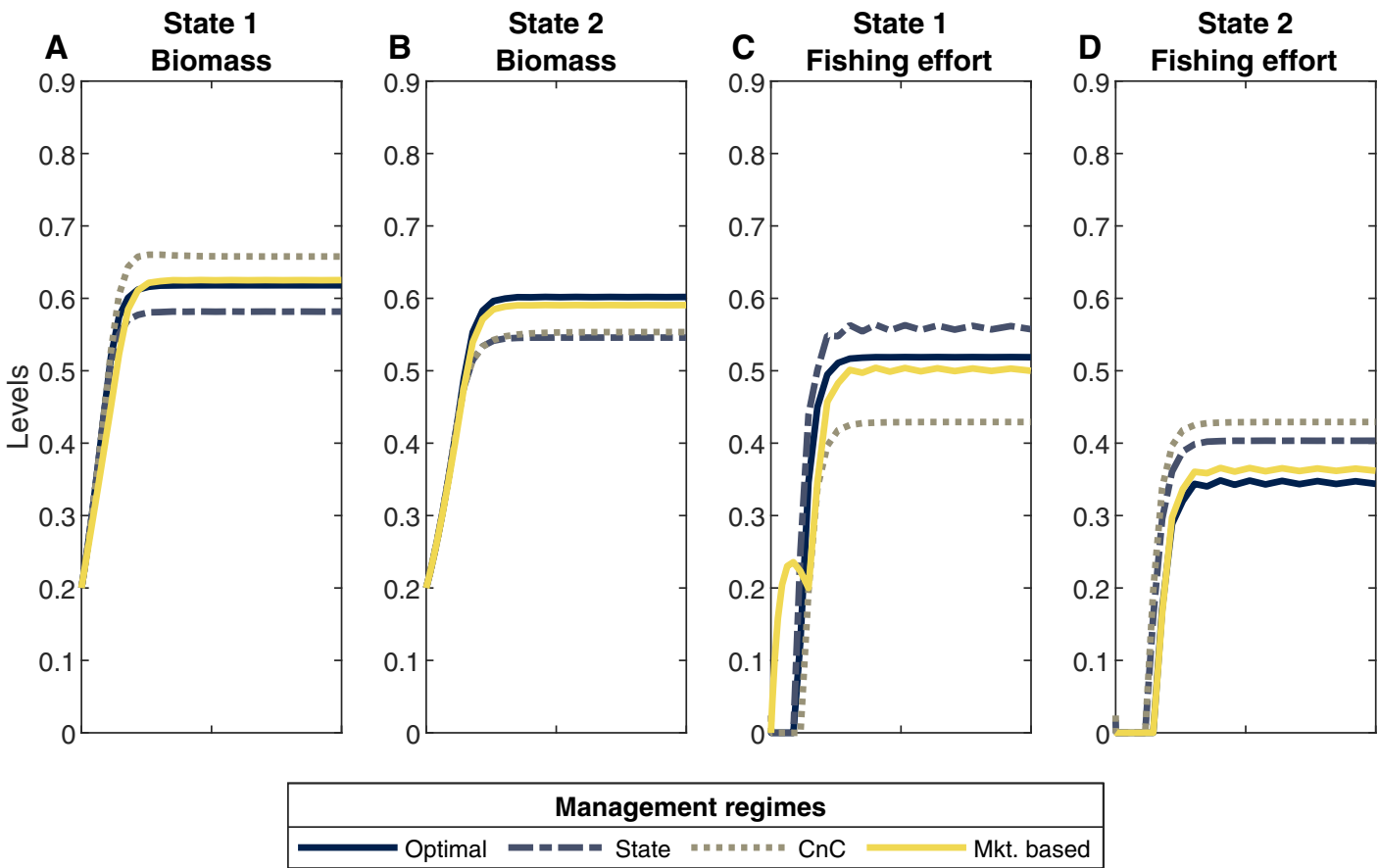

\section{Economic heterogeneity}
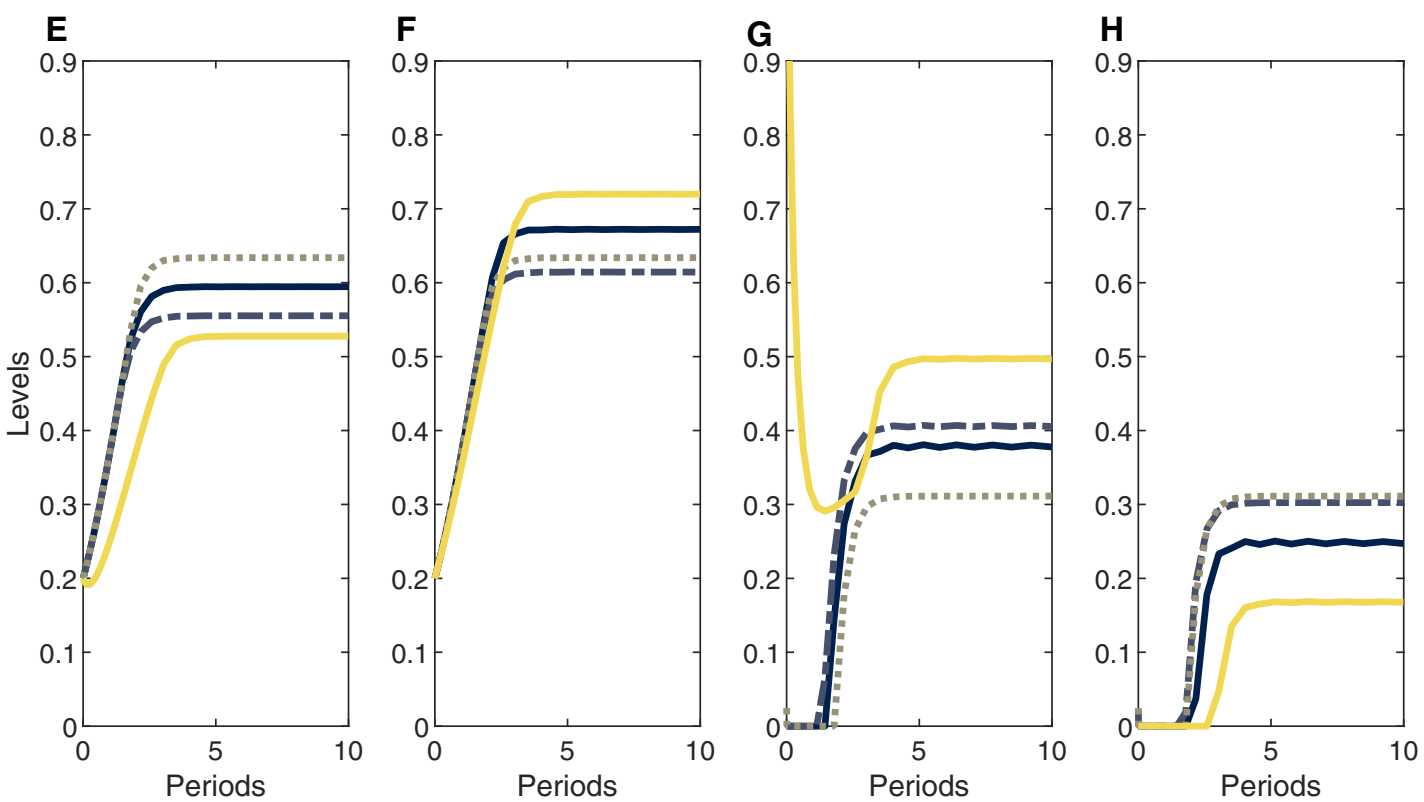

FIG. 2. Optimal biomass and fishing effort dynamic trajectories across the different management regimes (optimal, state, command and control $[\mathrm{CnC}]$, and market based). The case presented captures a medium dispersal rate scenario $(d=0.26$, which is approximately $70 \%$ of the maximum rate assumed in our analysis) and high heterogeneity scenario $\left(r_{1}\right.$ [Panels A-D] and $c_{21}$ [Panels E-H] are both approximately $62 \%$ greater than the other states' parameters, respectively). The $y$-axis represents levels of biomass (Panels A-B and E-F) and fishing effort (Panels C-D and $\mathrm{G}-\mathrm{H}$ ), and the $x$-axis represents the first 10 periods.

both states prefer decentralized state management (dark red regions in Fig. 4) when the states are very different and the resource is relatively stationary. The specific degree of state heterogeneity and resource dispersal needed to achieve consensus varies depending on the policy employed by the federal government and the 


\section{Biological heterogeneity}

A

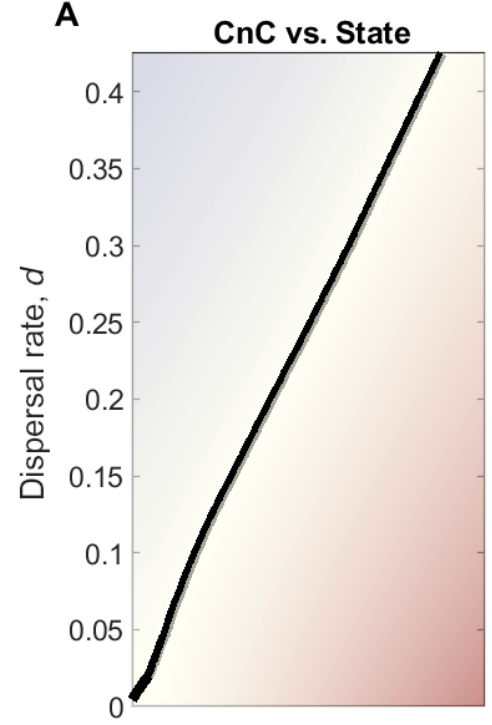

B

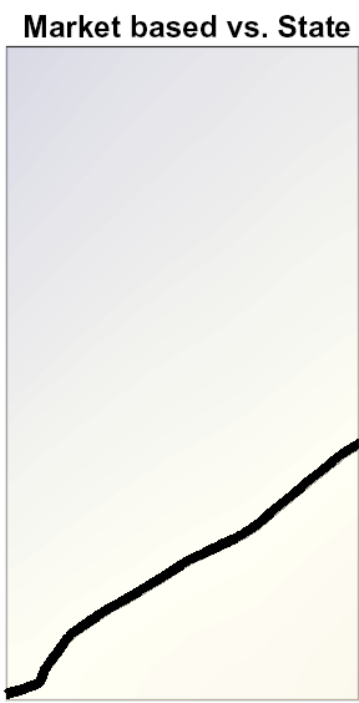

C

\section{Federal vs. State}

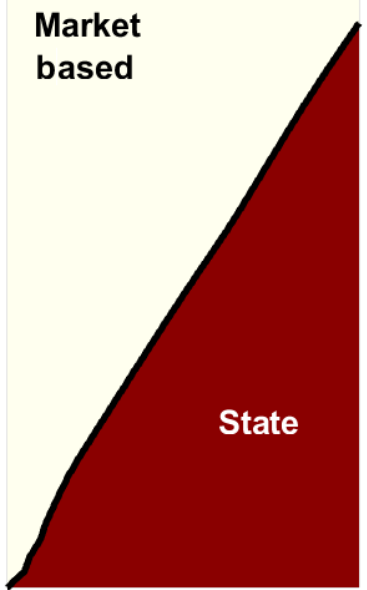

\section{Economic heterogeneity}

D

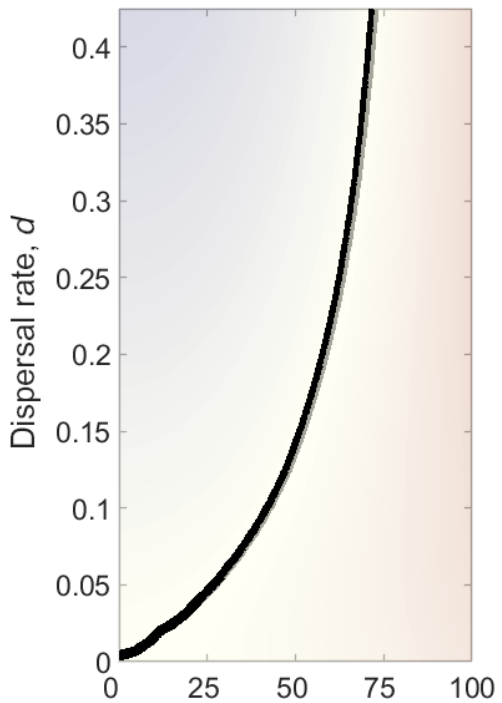

$-5$

\section{Difference in NPV (\%)}

15

$\mathbf{F}$
E

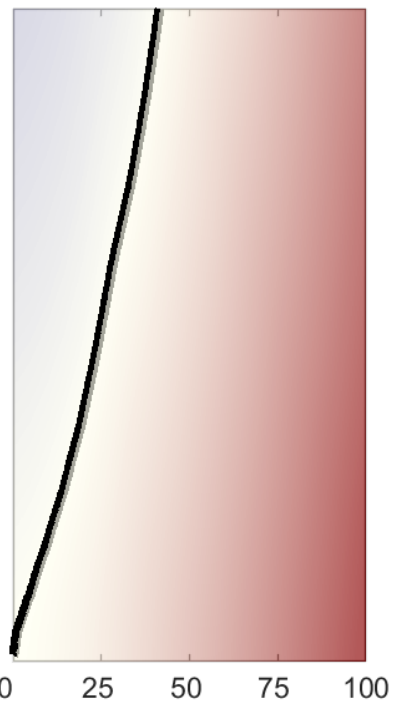

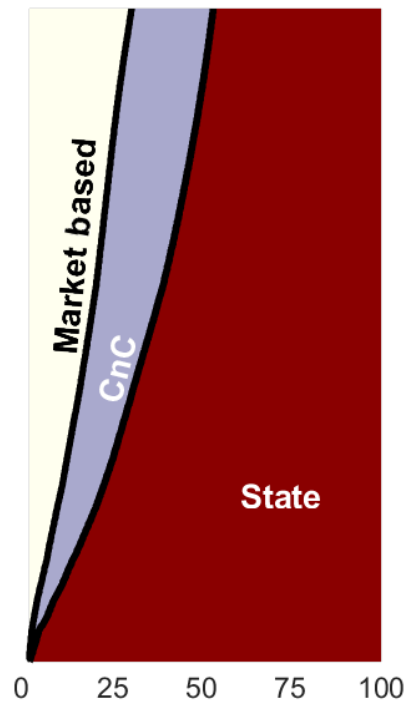

\section{Spatial heterogeneity difference between states (\%)}

FIG. 3. Federal vs. state management for an over-exploited resource under (A-C) biological heterogeneity and (D-F) economic heterogeneity. For a given uniform federal management type (command and control or market based), the heat map (panels A, B and $\mathrm{D}, \mathrm{E}$ ) measures the percent difference between the net present value of profits under state and federal management. In panels $\mathrm{A}, \mathrm{B}$ and $\mathrm{D}, \mathrm{E}$, red zones indicate that state management performs better, while blue zones indicate that federal management performs better. Panels $\mathrm{C}$ and $\mathrm{F}$, indicate the absolute winner across all policies, where red signals state management yields the highest payoff, white signals the federal market-based policy yields the highest payoff, and blue signals the federal command and control policy yields the highest payoff. In all cases, the black contour lines represents zero, where there is no difference in economic performance between management regimes. 


\section{Biological heterogeneity}

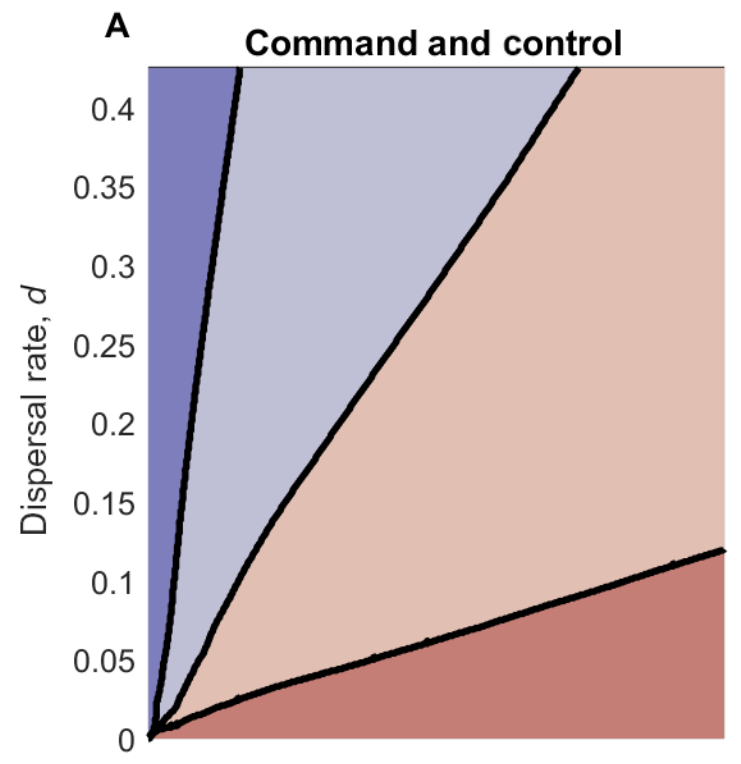

B

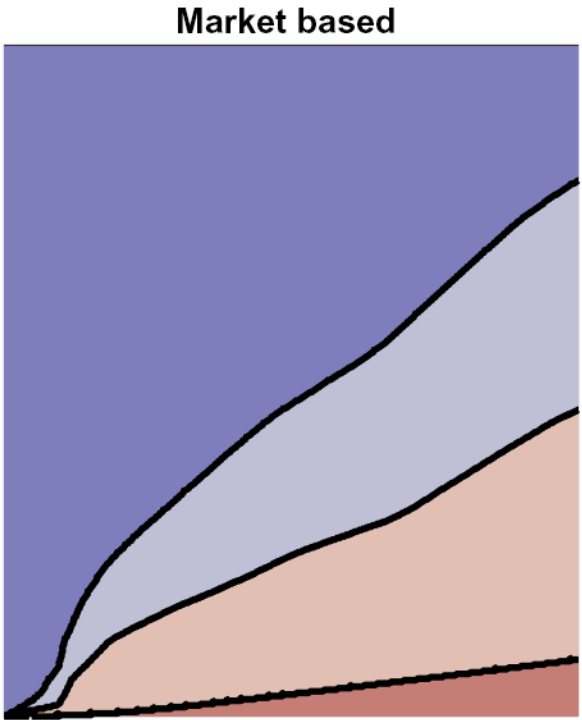

\section{Economic heterogeneity}

\section{C}

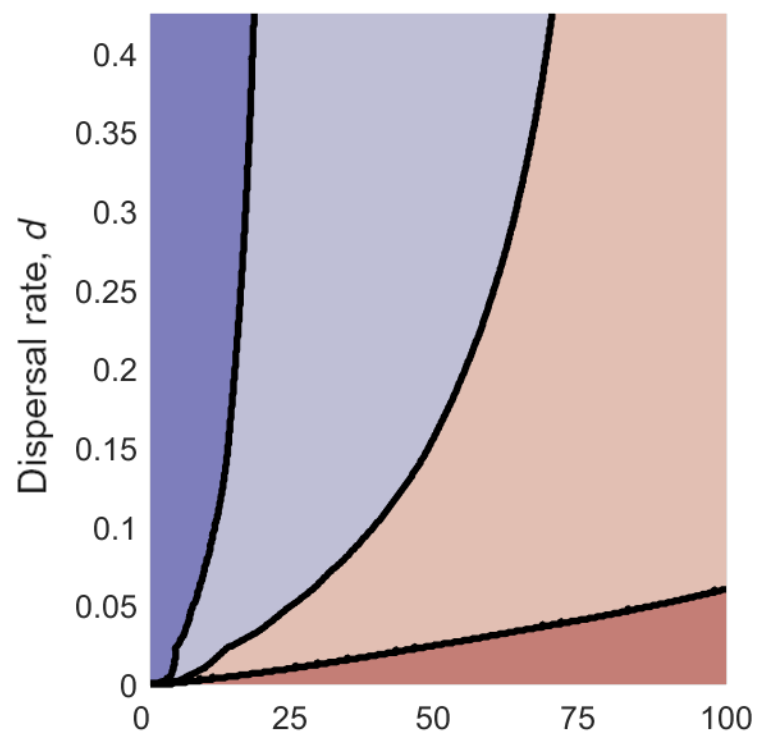

Federal

State

\section{D}

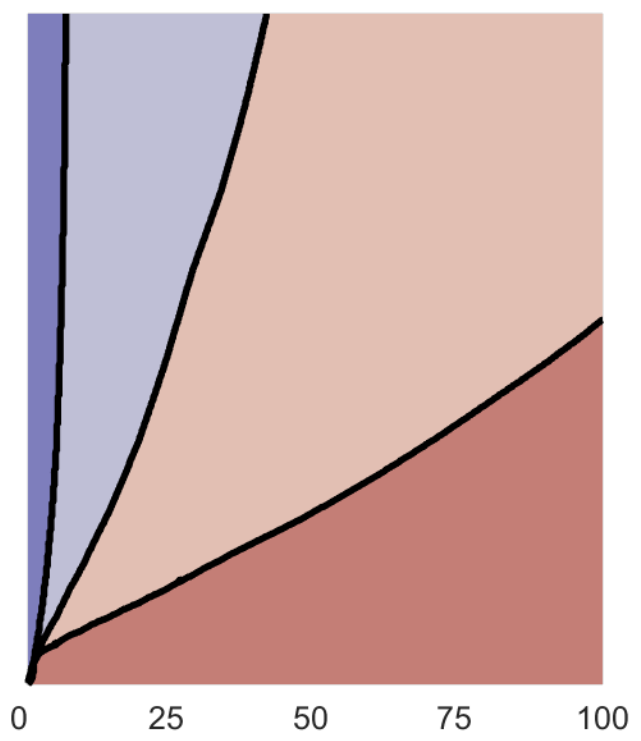

\section{Spatial heterogeneity difference between states (\%)}

FIG. 4. Fairness implications of federalism. All panels show the preferences of the states to different levels of management. Dark red indicates both states prefer state-level management, dark blue indicates both states prefer federal management. Light red (blue) indicates that one state prefers federal management and the other prefers state management but the total value of the resource is largest under state (federal) management. Preference is defined as differences in the state's net present value in the different management regimes. Panels A and B compare state management to federal management (command and control or market based) with biological heterogeneity between states. Panels $\mathrm{C}$ and $\mathrm{D}$ compare state management to federal management (command and control or market based) with economic heterogeneity between states. 
source of heterogeneity. However, consensus is most common when the federal government employs a market-based approach (Fig. 4B and D). With biological heterogeneity, there is often unanimous support for a federal market-based approach (Fig. 4B) while unanimous support for decentralized state management is more common with economic heterogeneity (Fig. 4D).

States may also disagree over the preferred management regime (light blue and red areas in Fig. 4). When disagreements arise, one state gains from a particular management regime and the other state loses. Disagreements are particularly important since debates about the appropriate level of management are often resolved through a democratic process where each state has some input in the decision. For example, if changes in management regime are decided by majority rule, disagreements between states may prevent policies designed to protect an over-exploited resource. Disagreements generally arise because state 1 prefers state-level management (Appendix S1: Fig. S2) and state 2 prefers federal-level management (Appendix S1: Fig. S3) and are more common when the federal government imposes a uniform effort policy rather than a market-based policy.

While disagreements between states can perpetuate inefficient use of the resource, the state that gains from a particular management regime can compensate the loser for their losses in that management regime (i.e., a side payment). These side payments are mutually beneficial and can resolve any disagreements and produce consensus. For example, in the light blue (red) areas in Fig. 4, there is disagreement but one state could compensate the other leading to unanimous support for federal (state) management. The boundary between the light blue and light red areas is where there is no difference in economic performance between management regimes. Near this boundary, there is also little economic gain from a particular management regime. This suggests that disagreements over management regimes are more likely when the aggregate gains from a particular management regime are relatively low.

Up to here, we have focused on the problem of rebuilding an over-exploited resource starting from a status quo of no management. However, many current federal-state conflicts involve transferring management authority from one level of government to another, as is currently being discussed with the commercial Red Snapper fishery in the Gulf of Mexico (Hotakainen 2017). Now we ask, under what conditions does the total value of the system increase when switching from one regime to another (e.g., state to federal market-based system), and which states support the switch, if any (e.g., state 1 or state 2)? Switching entails adjustments to the fishing effort levels, which in turn leads to adjustments in the fish stocks over time as the levels in each state converge toward a new steady state (Appendix S1:Fig. S5 illustrates the adjustment paths of the fish stocks). In some cases, these adjustments result in increases in per period economic profit relative to the status quo and in some cases these adjustments result in losses. In Fig. 5, we show the preference to switch or remain in the status quo based on the system-wide discounted sum of these per period profits (NPV).

When the status quo is a federal policy imposing uniform effort levels (Fig. 5A and C), incentives to switch to a state-based policy exist when there are large differences in local conditions (both ecological and economic). The reverse is also true, in that when starting at a state policy, both states prefer to remain in that system under high levels of heterogeneity (Fig. 5E and G). Where the preferences switch, however, in these two cases varies and is not symmetric across the different status quo settings (black lines in Fig. 5A, C, E, and G). These differences stem from the particulars of each scenario, including the status quo steady-state levels, which vary based on the underlying local conditions and dispersal, the endogenous response of biological dispersal to the switch in the management regime, and the required actions to adjust the system from one steady state to another.

Because the losses from imposing a market-based federal policy under biological heterogeneity are minimal compared to the first-best (Fig. 1B), the fact that the federal policy is preferred regardless of the status quo is not surprising (Fig. 5B and F). The exception is when there is low dispersal and the starting point is state management (Fig. 5F). Even in this case, the gains from staying are essentially zero (shading in Fig. 5 represents the NPV gains in staying or switching).

While the above analysis varies the nature and degree of heterogeneity in the system along with the dispersal rates, some conditions are held fixed, such as the discount rate, initial case of starting from an exploited system, and the nature of the cost heterogeneity. We ran a number of sensitivity analyses to determine whether changing these underlying parameters impacts the qualitative nature of our solutions. Specifically, we ran the same sets of analyses with a high discount rate $(\delta=0.10$, Appendix S1: Figs. S7-S10) and a low discount rate $(\delta=0$, Appendix S1: Figs. S11-S14). The qualitative nature of the solutions is robust to these changes. We did find, however, that the shape of the regions where one type of regime is favored over another is impacted, but the overall location of the regions in the heterogeneity-spillover space is similar. The results are also robust to starting out with a relatively unexploited fish stock level $(80 \%$ of carrying capacity, Appendix S1: Figs. S15-S18), where the optimal dynamic paths of fishing effort fish down the fish stock to their new steady-state levels. Finally, we considered the case where rather than increasing the marginal cost of fishing in patch 2 , we decrease the cost of fishing in patch 1 to investigate whether results vary since these scenarios lead to a more profitable 


\section{Federal to State}

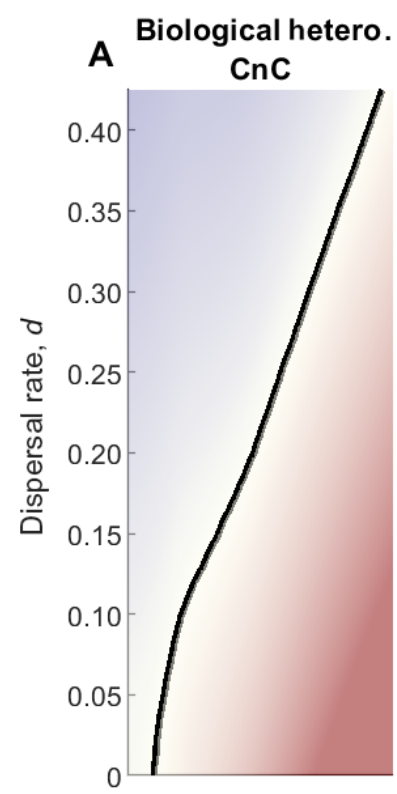

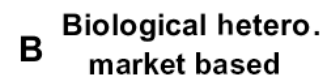

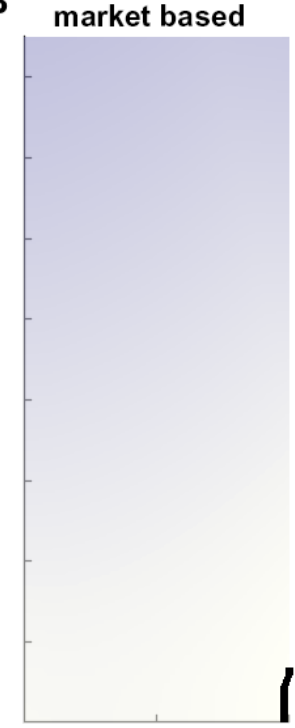

C Economic hetero.

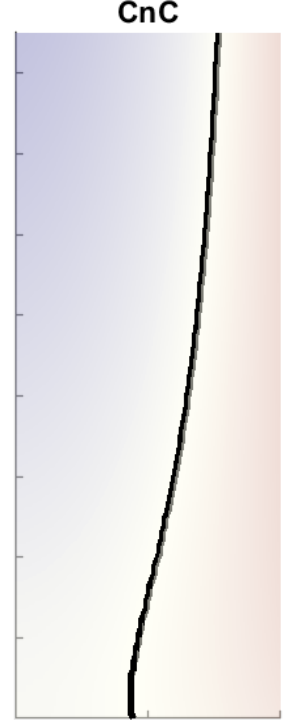

Economic hetero.
market based

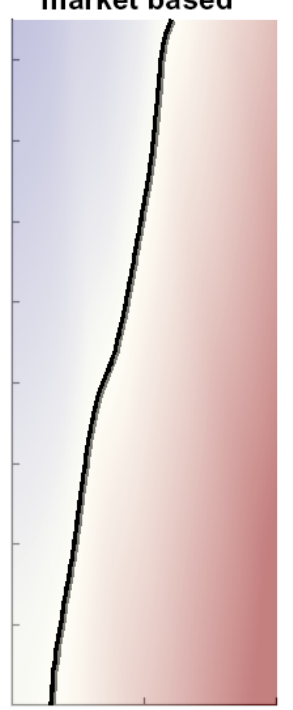

\section{State to Federal}

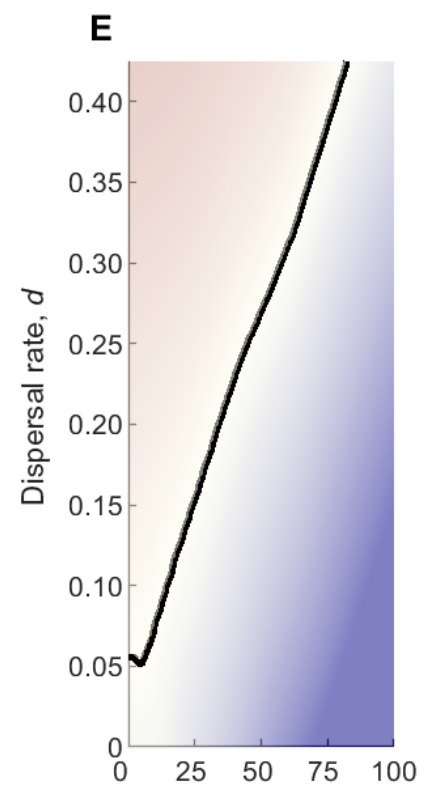

$\mathbf{F}$

\section{Stay}

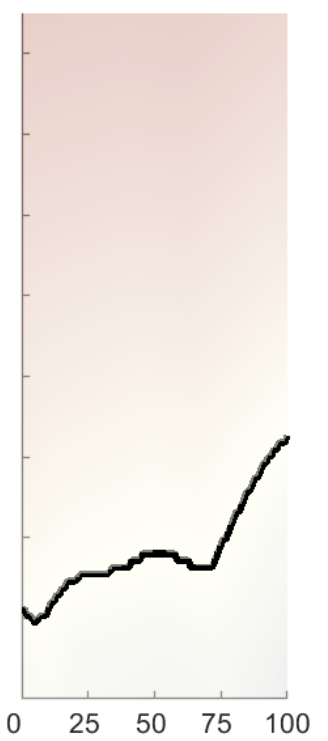

G

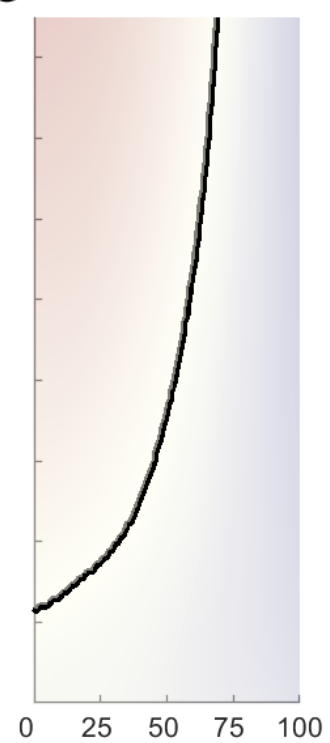

H

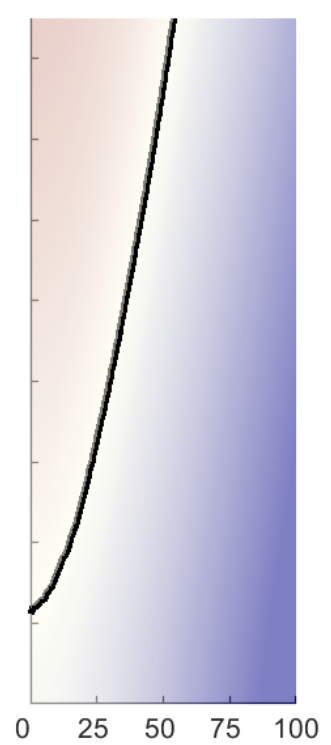

\section{Spatial heterogeneity difference between states (\%)}

FIG. 5. Preferences for switching between federalism regimes. The heat map in each panel measures the percent difference between the net present value of rents under status quo management and a change in management regime. Federal management is the status quo in Panels A-D and state management is the status quo in Panels E-H. Panels A-B and E-F vary biological heterogeneity, and Panels C-D and G-H vary economic heterogeneity. Panels A, C, E and G evaluate the federal uniform effort policy and Panels B,D,F, and $\mathrm{H}$ evaluate the federal market-based policy. In each panel, the initial conditions are the steady-state under the status quo, which varies with the underlying heterogeneity (horizontal axis) and dispersal rate (vertical axis). 
fishery overall. The results are symmetric to the nature of the cost changes.

\section{Discussion}

Renewable resource federalism presents a spectrum of management alternatives, characterized by the level of government at which authority is located, the structure of the policy applied, and the degree to which inter-state uniformity constrains decision making. For a given federalism alternative, we find that economic performance, ecological outcomes, and the implications for fairness are determined by the heterogeneity and connectivity in the spatial dynamics of the managed resource.

Broadly speaking, our results are consistent with the environmental federalism work on pollution control characterized by fixed, unidirectional spillover of pollutants from one jurisdiction to another, even though in our setting the direction and magnitude of biomass spillover is endogenous and varying over time. One difference is that, while we find that decentralized control leads to higher levels of exploitation than the first best policy, classifying the "state" managers as racing to the bottom is not a fait accompli. The steady-state stock sizes we find are all above U.S. fishery management thresholds for overfished stocks (Dept. of Commerce 2016). With renewable resources, the level of the stock drives the overall productivity of the fishery, while pollution is part of the waste stream associated with production of a valuable commodity. Of course, there might be settings where state management is incapable of monitoring and enforcing fishery regulations that could lead to a race to the bottom; in our setting, we assumed that institutions to manage the resource where available at each scale and equally effective. Future work could consider different management capacities at the different scales of governance and how that can feed back into benefits and costs of renewable resource federalism debates.

The implications of federalism for the economic value and fairness of natural capital management are increasingly the focus of public policy debates. While our broad patterns are consistent with the prior literature, we uncover several situations that cast a shadow on using simple rules of thumb when discussing the benefits and costs of one scale of control over another. We find that the key mechanisms behind the trade-offs across the different management regimes include whether differences in local conditions are driven by biological or economic mechanisms, whether the federal government employs uniform command and control or market-based policies, the spatial and temporal distribution of economic returns across the locales, and the status quo management regime. While spillover and local forms of heterogeneity were a focus of the earlier literature (notably Costello and Kaffine 2017), the roles that different types of federal control, the nature of the heterogeneity, and the status quo management regime play in determining the benefits and costs of federalism are key insights into the political-economy discussions around renewable resource federalism.

There are a number of possible extensions to our model that would permit the analysis of additional political economy dimensions of renewable resource federalism. For example, we do not consider administrative costs due to switching, which given that some of the gains to switching are quite small could swamp the decision on whether to remain or switch to another regime. Market linkages, for example through output markets, can also create cross-jurisdictional spillover that could affect the preferences for different scales of government regulation. We also abstracted away from ecological complexity by considering a biomass model with a single per-capita dispersal rate. Multiple species trophic models with varying dispersal rates across the trophic levels are more realistic and will likely provide interesting trade-offs across species and one-size-fits-all policies. Dispersal patterns across habitats and life stages, which are often spatially explicit, are also important to consider. In general, the ecological influence on economic outcomes has received only limited attention in analyses of federalism; we believe our research argues for more attention to these issues. Furthermore, the complexity of many of the comparisons we make would not have been possible to uncover without our dynamic optimization approach. To provide useful insight into the merits of federalism alternatives for a given resource, we argue that future analysis should similarly adopt a dynamic perspective that accounts for how the given context of resource growth and movement across space can determine the performance of management.

While our modeling approach provides several new insights, our results also suggest that a great deal must be known about the biology and economics of a resource in order to rank federal and state policies. An important empirical question when undertaking these comparisons is how much of the efficiency gains from the first-best policy can be achieved by federal uniform (second-best) policies. If federal one-size-fits-all polices can capture most of the efficiency gains from state-specific policies, federal management likely represents the preferred approach. Recent empirical work suggests that the efficiency costs of federal policies can be approximated using simple regression statistics (Jacobsen et al. 2020). Adapting these methods for renewable resource management represents a potentially fruitful avenue for future work.

\section{METHODS}

\section{Bioeconomic model}

The biological component of our model represents the continuous-time dynamics of two harvested fish stocks, 
$x_{1}(t)$ and $x_{2}(t)$, the populations of which are connected by dispersal (Sanchirico and Wilen 2005, Moeller and Neubert 2015)

$$
\frac{d x_{i}}{d t}=r_{i} x_{i}(t)\left(1-\frac{x_{i}(t)}{K_{i}}\right)-d\left(x_{i}(t)-x_{j}(t)\right)-q_{i} E_{i}(t) x_{i}(t) .
$$

Here $i, j \in\{1,2\}$ index states, with $j \neq i$.

The stocks grow logistically, with intrinsic rate of increase $r_{i}$ and carrying capacity $K_{i}$, in each state $i$. Fish move from one state to the other at a constant per-capita rate, $d$. Fishing mortality in state $i$ is the product of fishing effort $E_{i}(t)$ and $q_{i}$, the catchability in state $i$.

The economic value of fishing is measured through the rate of fishing profit accumulation at the state level

$$
\pi_{i}\left(x_{i}(t), E_{i}(t)\right) \equiv\left(p_{i} q_{i} x_{i}(t)-\left[c_{i 1}+c_{i 2} E_{i}(t)\right]\right) E_{i}(t) .
$$

Fishing profit $\pi_{i}(t)$ received by state $i$ depends on the landings price $p_{i}$, the current stock level in the state's fishery, and costs of fishing effort that are sensitive to short-run adjustment (via cost-of-effort parameters $c_{i 1}$ and $c_{i 2}$ ). The net present value of the current and future profits flowing to state $i$ is then

$$
J_{i}\left(E_{i}\right)=\int_{0}^{\infty} \pi_{i}\left(x_{i}(t), E_{i}(t)\right) e^{-\delta t} d t
$$

subject to the population dynamics (Eq. 1); $\delta$ is a conventional discount rate.

For all types of federal management, the objective is to maximize $J_{1}\left(E_{1}(t)\right)+J_{2}\left(E_{2}(t)\right)$ by managing the path of fishing effort in each state $E_{i}(t)$ subject to Eqs. 1 and 2, initial conditions for the fish population $\left(\mathbf{x}_{0}\right)$ and non-negativity constraints, $\mathbf{x}(t) \geq 0$ and $E_{i}(t) \geq 0 \forall t$. First-best federal management selects optimal effort paths (see the Appendix S1: Section S1.1 for further details).

Spatially uniform federal policies impose additional constraints on effort. Under the optimal uniform effort policy, the federal government maximizes the NPV of fishery profits while enforcing an equal amount of fishing effort in each state such that $E_{1}(t)=E_{2}(t) \forall t$ (see the Appendix S1: Section S1.2 for further details). Alternatively, under the uniform market-based policy, the federal government chooses the optimal paths of fishing effort that satisfy

$$
\frac{\partial \pi\left(x_{1}(t), E_{1}(t)\right)}{\partial E_{1}(t)}=\frac{\partial \pi\left(x_{2}(t), E_{2}(t)\right)}{\partial E_{2}(t)} \forall t
$$

Imposing this constraint is akin to a uniform quota price (marginal value of an additional unit of the fish stock) that results when two fishing quota markets are linked via quota trading (Sanchirico and Wilen 2005). For this reason, we label this policy as market-based (see the Appendix S1: Section S1.3).

When management of the fishery is decentralized, we model the state-level policy as the outcome of a non-cooperative dynamic game (Kamien and Schwartz 1991). In this game, state $i$ anticipates the time path of fishing effort chosen by state $j$ and solves its optimization accordingly $(i \in\{1,2\}$ while $j \in\{1,2\}$ such that $i \neq j$ ). For example, state $i$ solves the following optimization problem:

$$
\hat{J}_{i}\left(\bar{E}_{j}(t)\right)=\max _{E_{i}(t)} \int_{0}^{\infty} \pi_{i}\left(x_{i}(t) E_{i}(t)\right) e^{-\delta t} d t
$$

subject to

$$
\frac{d x_{i}}{d t}=r_{i} x_{i}(t)\left(1-\frac{x_{i}(t)}{K_{i}}\right)-d\left(x_{j}(t)-x_{i}(t)\right)-q_{i} E_{i}(t) x_{i}(t)
$$

$$
\frac{d x_{j}}{d t}=r_{j} x_{j}(t)\left(1-\frac{x_{j}(t)}{K_{j}}\right)-d\left(x_{i}(t)-x_{j}(t)\right)-q_{j} \bar{E}_{j}(t) x_{j}(t) .
$$

Here $\bar{E}_{j}(t)$ is the time path of fishing effort state $i$ anticipates state $j$ will choose, and $\hat{J}_{i}\left(\bar{E}_{j}(t)\right)$ is the maximized net present value of profits in patch $i$ conditional on the time path of effort in state $j$. State $i$ 's optimization is also subject to initial conditions and non-negativity constraints on effort and stock levels discussed above. See the Appendix S1: Section S1.4 for further details.

A Nash equilibrium in management strategies is one where neither state has an incentive to deviate from their own strategy. To solve the game, we take a direct approach to finding open-loop solutions, so-called because it performs direct numerical optimization of each state's objective functional using pseudo-spectral collocation (Benson et al. 2006). Specifically, we utilize pseudo-spectral collocation and nonlinear optimization to maximize an approximation of $\hat{J}_{i}\left(\bar{E}_{j}(t)\right)$ over a long but finite time horizon subject to the problem constraints and the current guess for state $j$ 's fishing strategy, and vice versa. This process iterates until the sum $\hat{J}_{1}\left(\bar{E}_{2}(t)\right)+\hat{J}_{2}\left(\bar{E}_{1}(t)\right)$ converges, producing open-loop Nash equilibrium controls $E_{i}^{\mathrm{G}}(t)$. Additional details on our solution method are provided in the Appendix S1: Section S2. Applications of methods to solve dynamic games appear to be rare and either focused on indirect methods (based on solving the state and co-state Hamiltonian canonical system of ordinary differential equations) or limited to problems with special structure (Dockner et al. 2000, Guangyan et al. 2016, Nikooeinejad et al. 2016, Costello and Kaffine 2017).

We solve all variations of the federal government's problem using the same direct pseudo-spectral methods we apply in our algorithm for the state-level problem. 
Evaluations of the relative performance of the management regimes are measured through comparing NPV of state-level profits when different solutions are applied. For example, we compare the NPV of first-best solution to the NPV of the command-and-control (C) solution, where the optimal spatially uniform effort policy $E^{\mathrm{C}}(t)$ is first computed and then inputted to evaluate $J_{1}\left(E^{\mathrm{C}}(t)\right)+J_{2}\left(E^{\mathrm{C}}(t)\right)$. Similarly, with the solutions $E_{i}^{\mathrm{G}}(t)$ to the decentralized alternative computed, we aggregate NPV by evaluating $J_{1}\left(E_{1}^{\mathrm{G}}(t)\right)+J_{2}\left(E_{2}^{\mathrm{G}}(t)\right)$. Appendix S1: Section S3 describes how we calculate the NPV of switching from one regime to another.

\section{Model parameterization}

We solve for fishery dynamics under different management regimes while varying parameters that capture structural heterogeneity (e.g., $r_{i}$ and $c_{i 1}$ ) and spillover (dispersal rate parameter $d$ ). Anchoring this exploration of the model is a set of baseline parameter values chosen to facilitate solutions in the neighborhood of parameter space that are both well-behaved and informative (See Appendix S1:Table S1 for the levels).

\section{Acknowledgments}

This work was partially supported through the Ecological Federalism working group of the National Institute for Mathematical and Biological Synthesis, an Institute sponsored by the National Science Foundation through NSF Award (No. DBI-1300426), with additional support from the Howard H. Baker Jr. Center for Public Policy and The University of Tennessee, Knoxville. M. G. Neubert acknowledges support from the U.S. National Science Foundation (DEB-1558904) and from the J. Seward Johnson Endowment in support of the Woods Hole Oceanographic Institution's Marine Policy Center. We would like to thank seminar participants at Oregon State University, Nature Policy Lab at U.C. Davis, and the 2019 Association of Environmental and Resource Economists Summer Conference for valuable comments and suggestions on earlier versions of this research. All errors are the responsibility of the authors.

\section{Literature Cited}

Aden, J. 2001. Decentralization of natural resource sectors in indonesia: Opportunities and risks. World Bank EASES Discussion Paper Series \#23148.

Arrow, K. J., et al. 1996. Is there a role for benefit-cost analysis in environmental, health, and safety regulation? Science 272:221-222.

Barrett, S. 2016. Coordination vs. voluntarism and enforcement in sustaining international environmental cooperation. Proceedings of the National Academy of Sciences USA 113:14515-14522.

Benson, D. A., G. T. Huntington, T. P. Thorvaldsen, and A. V. Rao. 2006. Direct trajectory optimization and costate estimation via an orthogonal collocation method. Journal of Guidance, Control, and Dynamics 29:1435-1440.

Costello, C., and D. Kaffine. 2017. Natural resource federalism: Preferences versus connectivity for patchy resources. Environmental and Resource Economics 71: 99-126.
Crowder, L. B., et al. 2006. Resolving mismatches in U.S. ocean governance. Science 313:617-618.

Dannenberg, A., and S. Barrett. 2018. Cooperating to avoid catastrophe. Nature Human Behaviour 2:435.

Dept. of Commerce. 2016. 81 FR 71858 - Magnuson-Stevens Act Provisions; National Standard Guidelines (Volume 81, Pages 71858-71904). Office of the Federal Register, National Archives and Records Administration.

Dockner, E. J., S. Jorgensen, N. Van Long, and G. Sorger. 2000. Differential games in economics and management science. Cambridge University Press, Cambridge, UK.

Elliott, E. D., B. A. Ackerman, and J. C. Millian. 1985. Toward a theory of statutory evolution: The federalization of environmental law. Journal of Law, Economics, \& Organization $1: 313-340$

Epanchin-Niell, R. S., and J. E. Wilen. 2014. Individual and cooperative management of invasive species in human-mediated landscapes. American Journal of Agricultural Economics 97:180-198.

Fischer, R. D., and L. J. Mirman. 1992. Strategic dynamic interaction: Fish wars. Journal of Economic Dynamics and Control 16:267-287.

Fischer, R. D., and L. J. Mirman. 1996. The compleat fish wars: Biological and dynamic interactions. Journal of Environmental Economics and Management 30:34-42.

Guangyan, X., Z. Biao, and Z. Hongmei. 2016. Multi-player nonzero-sum nash differential game: Variation and pseudospectral method. Optimal Control Applications and Methods 38:506-519.

Hotakainen, R. 2017. Trump team may have broken law to score red snapper win. Green wire. https://www.eenews.net/ greenwire/stories/1060069413

Illical, M., and K. Harrison. 2007. Protecting endangered species in the us and canada: The role of negative lesson drawing. Canadian Journal of Political Science 40:367-394.

Jacobsen, M. R., C. R. Knittel, J. M. Sallee, and A. A. van Benthem. 2020. The use of regression statistics to analyze imperfect pricing policies. Journal of Political Economy 128:1826-1876.

Kamien, M. I., and N. L. Schwartz. 1991. Dynamic optimization: The calculus of variations and optimal control in economics and management. Second edition. Elsevier, San Francisco, California, USA.

Kling, D. M., J. N. Sanchirico, and J. E. Wilen. 2016. Bioeconomics ofmanaged relocation. Journal of the Association of Environmental and Resource Economists 3:1023-1059.

Kunce, M., and J. F. Shogren. 2002. On environmental federalism and direct emission control. Journal of Urban Economics $51: 238-245$.

Kunce, M., and J. F. Shogren. 2005. On interjurisdictional competition and environmental federalism. Journal of Environmental Economics and Management 50:212-224.

Levhari, D., and L. J. Mirman. 1980. The great fish war: An example using a dynamic Cournot-Nash solution. Bell Journal of Economics 11:322-334.

Libecap, G. D. 2018. Federal lands, opportunity costs, and bureaucratic management (No. w24705). National Bureau of Economic Research.

List, J. A., and C. F. Mason. 2001. Optimal institutional arrangements for transboundary pollutants in a second-best world: Evidence from a differential game with asymmetric players. Journal of Environmental Economics and Management 42:277-296.

Moeller, H. V., and M. G. Neubert. 2015. Economically optimal marine reserves without spatial heterogeneity in a simple twopatch model. Natural Resource Modeling 28:244-255. 
Muller, N. Z., and R. Mendelsohn. 2009. Efficient pollution regulation: Getting the prices right. American Economic Review 101:1649-1675.

Munro, G. R. 1979. The optimal management of transboundary renewable resources. Economic Studies 41:37-50.

Nikooeinejad, Z., A. Delavarkhalafi, and M. Heydari. 2016. A numerical solution of open loop nash equilibrium in nonlinear differential games based on chebyshev pseudospectral method. Journal of Computational and Applied Mathematics 300:369-384.

Oates, W. E. 2001. A reconsideration of environmental federalism. Resources for the Future Discussion Paper 01-54 https://media.rff.org/archive/files/sharepoint/WorkImages/ Download/RFF-DP-01-54.pdf.

Oates, W. E., P. R. Portney, and A. M. McGartland. 1989. The net benefits of incentive based regulation: A case study of environmental standard setting. American Economic Review 79:1233-1242.

Oates, W. E., and R. M. Schwab. 1988. Economic competition among jurisdictions: Efficiency enhancing or distortion inducing? Journal of Public Economics 35:333-354.

Phillipson, J., and D. Symes. 2018. 'A sea of troubles': Brexit and the fisheries question. Marine Policy 90:168-173.

Ruple, J. C. 2018. The transfer of public lands movement: The battle to take back lands that were never theirs. Colorado Natural Resources, Energy, \& Environmental Law Review 29:1.
Sanchirico, J. N., and J. E. Wilen. 1999. Bioeconomics of spatial exploitation in a patchy environment. Journal of Environmental Economics and Management 37:129-150.

Sanchirico, J. N., and J. E. Wilen. 2005. Optimal spatial management of renewable resources: Matching policy scope to ecosystem scale. Journal of Environmental Economics and Management 50:23-46.

Sims, C., D. Aadland, and D. Finnoff. 2010. A dynamic bioeconomic analysis of mountain pine beetle epidemics. Journal of Economic Dynamics and Control 34:2407-2419.

Smith, M. D., J. N. Sanchirico, and J. E. Wilen. 2009. The economics of spatial-dynamic processes: Applications to renewable resources. Journal of Environmental Economics and Management 57:104-121.

Ulph, A. 2000. Harmonization and optimal environmental policy in a federal system with asymmetric information. Journal of Environmental Economics and Management 39:224-241.

Wellisch, D. 1995. Locational choices of firms and decentralized environmental policy with various instruments. Journal of Urban Economics 37:290-310.

\section{SUPPORTING INFORMATION}

Additional supporting information may be found online at: http://onlinelibrary.wiley.com/doi/10.1002/eap.2276/full

$$
\text { Data Availability }
$$

Sample Matlab code can be found at https://doi.org/10.5281/zenodo.4034965 